\title{
A Temperature Independent Inclinometer Based on a Tapered Fiber Bragg Grating in a Fiber Ring Laser
}

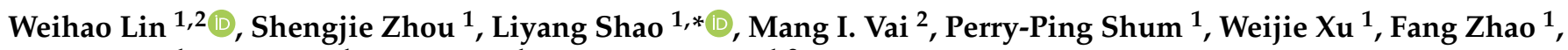 \\ Feihong Yu ${ }^{1}$, Yibin Liu ${ }^{1}$, Yuhui Liu ${ }^{1}$ and Shuaiqi Liu ${ }^{1,2}$ \\ 1 Department of Electrical and Electronic Engineering, Southern University of Science and Technology, \\ Shenzhen 518055, China; 11510630@mail.sustech.edu.cn (W.L.); 11812717@mail.sustech.edu.cn (S.Z.); \\ shenp@sustech.edu.cn (P.-P.S.); 11930535@mail.sustech.edu.cn (W.X.); 12031197@mail.sustech.edu.cn (F.Z.); \\ 11930480@mail.sustech.edu.cn (F.Y.); 11811808@mail.sustech.edu.cn (Y.L.); \\ 12068026@mail.sustech.edu.cn (Y.L.); 11853004@mail.sustech.edu.cn (S.L.) \\ 2 Department of Electrical and Computer Engineering, Faculty of Science and Technology, University of Macau, \\ Macau 999078, China; fstmiv@um.edu.mo \\ * Correspondence: shaoly@sustech.edu.cn; Tel.: +86-0755-8801-8136
}

check for updates

Citation: Lin, W.; Zhou, S.; Shao, L.; Vai, M.I.; Shum, P.-P.; Xu, W.; Zhao, F.; Yu, F.; Liu, Y.; Liu, Y.; et al. A Temperature Independent Inclinometer Based on a Tapered Fiber Bragg Grating in a Fiber Ring Laser. Sensors 2021, 21, 2892. https:// doi.org/10.3390/s21092892

Academic Editor:

Elżbieta Bereś-Pawlik

Received: 18 March 2021

Accepted: 15 April 2021

Published: 21 April 2021

Publisher's Note: MDPI stays neutral with regard to jurisdictional claims in published maps and institutional affiliations.

Copyright: (c) 2021 by the authors. Licensee MDPI, Basel, Switzerland. This article is an open access article distributed under the terms and conditions of the Creative Commons Attribution (CC BY) license (https:// creativecommons.org/licenses/by/ $4.0 /)$.

\begin{abstract}
We demonstrate a new concept for an all-fiber inclinometer based on a tapered fiber Bragg grating ( $\mathrm{tFBG}$ ) in a fiber ring laser (FRL) with the capability of measuring the tilt angle and temperature simultaneously. The sensor performance is analyzed theoretically and investigated experimentally. The dependence of tilt angle on the spectral response in variable temperature conditions was measured. Two inclinometers with different lengths have been fabricated and characterized in FRL. The sensitivity is $0.583 \mathrm{~dB} /{ }^{\circ}$ and $0.849 \mathrm{~dB} /{ }^{\circ}$, respectively, in the range of $0^{\circ}$ to $90^{\circ}$. Thanks to the FRL system, narrow $3-\mathrm{dB}$ bandwidth $(<0.1 \mathrm{~nm})$ and high optical signal-to-noise ratio $(\sim 60 \mathrm{~dB})$ are achieved. The tFBG in the FRL system can be used for working as a temperature insensitive inclinometer. The results suggested that the proposed inclinometer has the advantages of compact size and convenient manufacture, enhancing its potential for application prospect.
\end{abstract}

Keywords: inclinometer; tapered fiber Bragg grating; fiber ring laser

\section{Introduction}

Optical inclinometers have become excellent alternatives in many application fields, including offshore submarine pipeline cable monitoring [1,2], aviation [3], automatic machines [4], human health monitoring [5], etc., owing to their well-known advantages, for instance, immunity to electromagnetic interferences, high sensitivity, and compact size. In the last few decades, various kinds of techniques have been proposed based on metal or semiconductor materials [6] to exploit these inclinometers. However, the structure of the folding pendulum is fragile and not resistant to electromagnetic interference. Therefore, it is necessary to study inclinometers using different technologies to overcome these limitations. Besides, in other applications, for example, virtual reality technology, gesture recognition [7], intelligent machinery [8] and environment monitoring [9] a kind of inclinometer which is cost-effective, extremely accurate, and simple in structure is needed. Over the past few years, fiber-optic inclinometers have been widely investigated because of their inherent advantages, including long-term stability and reusability [10-13]. Therefore, they perform well under small inclination change conditions. Typically, optical fiber inclinometers consist of a fiber Bragg grating (FBG) [12], tilted fiber grating (TFG) [14] and long period fiber grating (LPFG) [15], etc. Besides, dislocation optical fibers [16] and multi-core optical fibers [17] are also used to manufacture inclinometers.

Liu et al. reported a tapered polymer fiber used as an inclinometer to measure tilt angles [18]. The detection sensitivity is as high as $4.23 \mathrm{~dB} /{ }^{\circ}$. Despite the high sensitivity of the polymer fiber, the temperature cross sensitivity and the cost of fabrication are 
fatal drawbacks. Tam et al. proposed an all-fiber two-dimensional inclinometer based on a fiber Bragg grating (FBG) which can simultaneously measure azimuth and inclination [17]. However, its manufacturing process is complicated. Tomasz et al. proposed a new measurement method based on FBG, realizing the detection range of $0^{\circ}-90^{\circ}$ [19]. Nevertheless, the output spectrum is chaotic. Kumar [12] reported an inclinometer base on a pendulum-based structure attached to its cantilever arm with an ultra-high resolution of $0.0008^{\circ}$. However, since, its complex structure the detection range is limited to $0-3^{\circ}$.

Nowadays, optical fiber ring laser sensors have become a hot topic due to their advantages of high signal-to-noise ratio and narrow 3-dB bandwidth [20-27]. Liu et al., proposed a cascaded MZI for strain sensing [28], successfully achieving a sensitivity of $52.5 \mathrm{pm} / \mu \varepsilon$. Martin-Vela et al. reported an inclinometer based on a fiber ring laser [29], where a thin core fiber modal interferometer worked as a filter for the system. Moreover, Fu reported a temperature sensing system based on a fiber ring microwave photonic filter (MPF) [30], which combined microwave photonics with a fiber ring laser. Mateusz proposed a FRL sensor which can simultaneously measure temperature and humidity [31]. Different types of inclinometers and accelerometers based on broadband light sources have been reported [32-34], yet to the best of our knowledge, the study of inclinometers based on a tapered fiber Bragg grating in a fiber ring laser has not been proposed.

In this letter, we propose a novel inclinometer based on tFBG in FRL. For the first time the tFBG was utilized in the fiber ring laser sensing system. In the range of $0^{\circ}$ to $90^{\circ}$, the $\mathrm{tFBG}$ has good temperature response and high sensitivity to inclination variations. Moreover, the change of tilt angle of reflection spectrum under different surrounding temperatures is examined. Furthermore, the elaborate design of the inclinometer in FRL system can choose between two kinds of monitoring instruments according to the specific application requirements. For the first method, the optical spectral analyzer is selected. The tilt angle is measured by detecting the change of light intensity, and the temperature is detected by the spectrum shift. The optical power meter is regarded as an inexpensive measuring tool to measure the tilt angle. It detects the total reflected power to judge the tilt angle without temperature interference. The experimental results show that the designed $\mathrm{tFBG}$ has a good response to the tilt angle. The sensitivity of the inclinometers is $0.583 \mathrm{~dB} /{ }^{\circ}$ and $0.849 \mathrm{~dB} /{ }^{\circ}$ in the range of $0-90^{\circ}$. Moreover, benefitting from the single peak output of the laser, the signal to noise ratio is as high as $60 \mathrm{~dB}$ and the linewidth is less than $0.1 \mathrm{~nm}$. Furthermore, the thinned central core is essential in the inclinometer for temperature detection. The proposed inclinometer has merits of high detection sensitivity, simple fabrication and low cost.

\section{Sensor Setup and Principle}

As shown in Figure 1. The designed inclinometer is consist of a tFBG stretched in one region. A commercial taper machine (6000 LE-H, Coupler Technology Co., LTD Shandong, China) was selected to fabricate the sensor. The filter of the presented inclinometer is actuality a section of TFBG written on head face of the fiber. Then, a $15 \mathrm{~mm}$ long fiber Bragg grating is written into a common single-mode fiber by using scanning phase mask and a continuous ultraviolet laser beam [35-37]. The production process includes two steps. The fiber stretching process consists of two steps. Firstly, the end of FBG is placed on the taper machine, and the nozzle is ignited to preheat the fiber. Secondly, the two electric displacement platforms are moved backward at a uniform speed, and the flame melts the fiber for taper. Symmetrical structures with total length of 4.5 and $3.7 \mathrm{~mm}$ and diameter of 75 and $86 \mu \mathrm{m}$ were obtained. In order to improve the photosensitivity of FBG, the $\mathrm{tFBG}$ cross section was hydrogasified at 120 bars for one week at $26{ }^{\circ} \mathrm{C}$. As shown in Figure 1. The fiber is tapered at the end of the FBG, leading to the spectral change. Thus, it is convenient to measure the tilt angle and detect the temperature. In the process of taper drawing, the taper structure and length of FBG are monitored in real time. As shown in Figures 2 and 3, the three-port optical circulator for connecting TFBG, light source and 
detector is optimized. The tilt angle is determined by analyzing the intensity change of OSA or optical power meter.

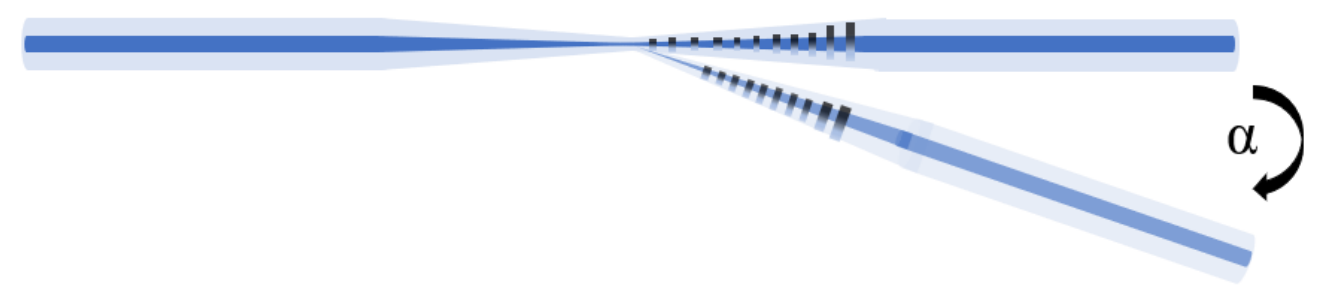

Figure 1. Schematic illustration of the inclinometer.

The working principle of the inclinometer is based on two phenomena: bending loss and selective reflection. Light from a laser source enters the fiber and then passes through the tFBG. When the fiber is bent, the mode field moves forward to one side of the tapered fiber. Therefore, a part of the optical power is coupled to the cladding region and finally dissipated. The rest of the radiation is shifted into the tFBG for selective reflection. Then it goes through the bend area again and is partially lost again. Finally, the output power spectrum is measured by a OSA or optical power meter. The light out of the wavelength range of the FBG passes through the grating and occurs the non-reflective terminal. The main advantage of tFBG is that based on the reflective optical system, the influence of optical power loss will appear twice, thus improving the sensitivity of the inclinometer. More importantly, the temperature is measured as close to the bending region as possible. Benefits from the FRL system, a narrow 3-dB bandwidth $(<0.1 \mathrm{~nm})$ and a high optical signal-to-noise ratio $(\sim 60 \mathrm{~dB})$ are obtained.

There are three possible transmission paths for incident light coupling into a tapered fiber. In the first optical path, the core wavelength of reflected light must satisfy the FBG filtering condition. The intensity of light decays twice through the taper region. The second optical path is that some cladding modes are re-coupled with the core in the taper region. The strength loss is transferred by the amplitudes of the core and cladding modes compensated in the taper region. The third path is in the core region. The incident light is coupled from the core to the cladding, then re-coupled to the core through the grating. The intensity of light attenuates in core mode.

In this work, the taper profile chosen is a balance between guaranteeing the adiabatic conditions and providing a relatively high bending sensitivity for the inclinometer being analyzed. The power of the lower mode will be transferred to the higher mode if the radius of the tapered fiber changes too fast along the length direction. Therefore, the waist diameter is small enough, the taper is no longer adiabatic. Besides, for ensuring reliable temperature measurement near the bending area, some restrictions are imposed on the maximum length of taper and the position of tFBG. On the other hand, the bending loss increases with the decrease of waist diameter. As shown in Figure 2, tapered fibers with $86 \mu \mathrm{m}$ and $75 \mu \mathrm{m}$ waist is selected.

The bending loss per unit length of step index tFBG can be expressed as follows [12]:

$$
\begin{gathered}
\alpha=\frac{1}{2}\left(\frac{\pi}{a W^{3}}\right)^{\frac{1}{2}}\left(\frac{U}{V K_{1} W}\right)^{2} \exp (-D \cdot R) \cdot R^{-\frac{1}{2}} \\
D=\frac{4 \Delta W^{3}}{3 a V^{2}}
\end{gathered}
$$

where $\alpha, R$ and $\Delta$ are the core radius, bending radius, and core-cladding refractive index difference, respectively. $K_{1}$ is a modified Hankel function. $U$ and $W$ are the transverse propagation constants in the core and cladding. $V$ is the normalized frequency. 

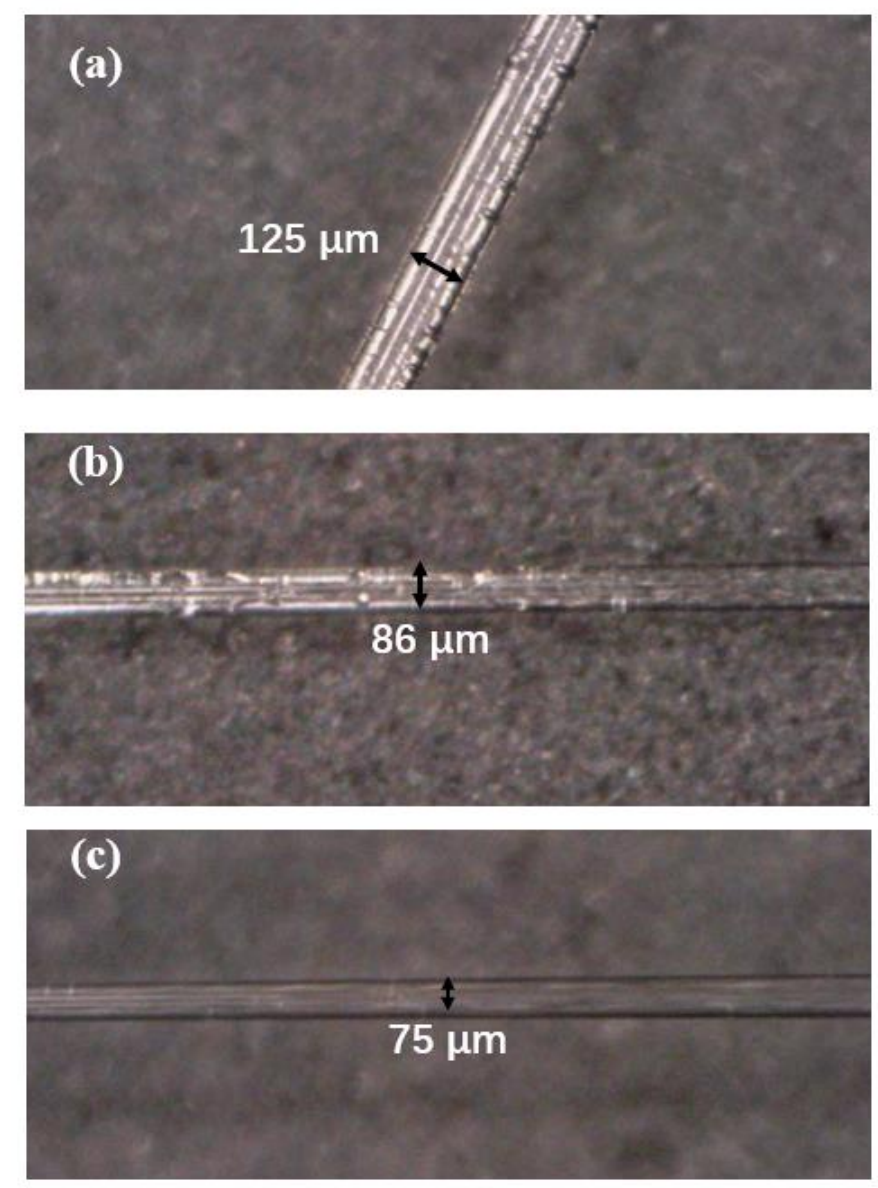

Figure 2. Microphotographs of different structures of the taper-shaped FBG, (a) with $125 \mu \mathrm{m}$ waist (b) with $86 \mu \mathrm{m}$ waist. (c) with $75 \mu \mathrm{m}$ waist.

To ensure reliable temperature sensing in the tFBG region, the maximum length and position of the taper are limited. In this work, we choose to taper at the end of FBG. According to the model provided by a Marcuse experiment $[38,39]$, the theory that the bending loss increases with the decrease of waist diameter is obtained.

A pre-experiment was set up to demonstrate the feasibility of the experimental scheme. As shown in Figure 3 the tFBG was linked with a circulator. Light from broadband light source transmitted to the circulator and reflected when pass through tFBG. The loss of intensity of light dependences on the tilt angle which could be further analyzed in OSA.

The experimental setup of the proposed inclinometer sensor is illustrated in Figure 4. A wavelength division multiplexer (WDM) is used to couple the laser light source in a $1.5 \mathrm{~m}$-long Er-doped fiber (EDF) that works as the gain medium. Besides, an isolator (ISO) is connected to prevent backscattering light. A polarization controller (PC) is embedded in the FRL sensor to regulate the polarization state. $1 \%$ port of output coupler is used to extract the light to OSA or optical power meter from the ring cavity for further analysis.

In conclusion, in order to ensure that the proposed structure has enough performance, we choose the parameters of TFBG through repeated experiments. Another way to measure the power spectrum of reflected light is to use an optical power meter instead of OSA. This can effectively reduce the cost of measurement. 


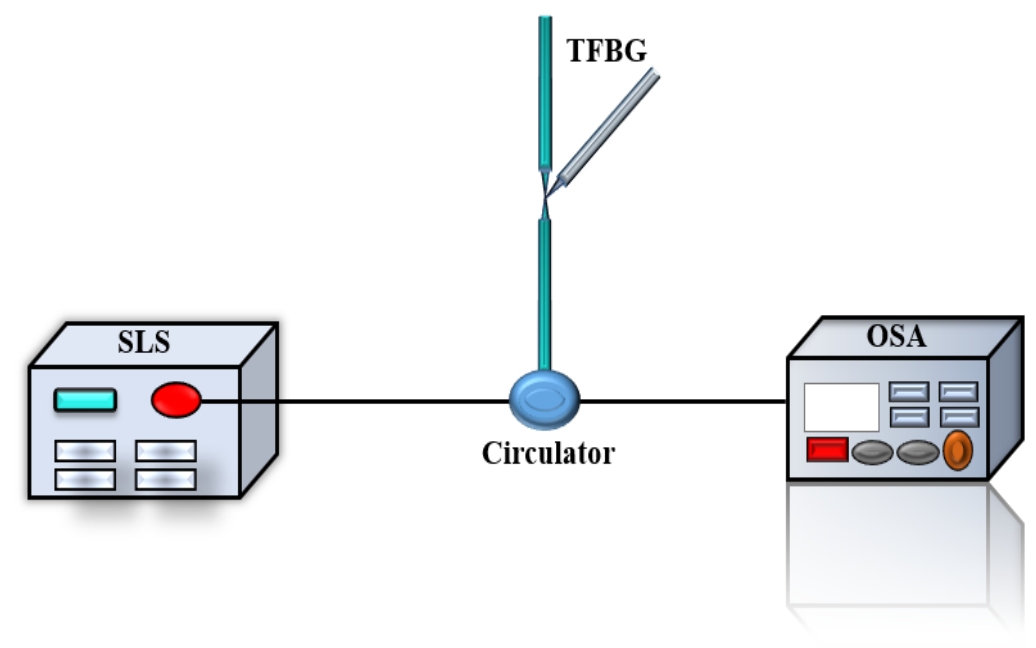

Figure 3. Schematic diagram of the experimental setup for the inclination measurement system.

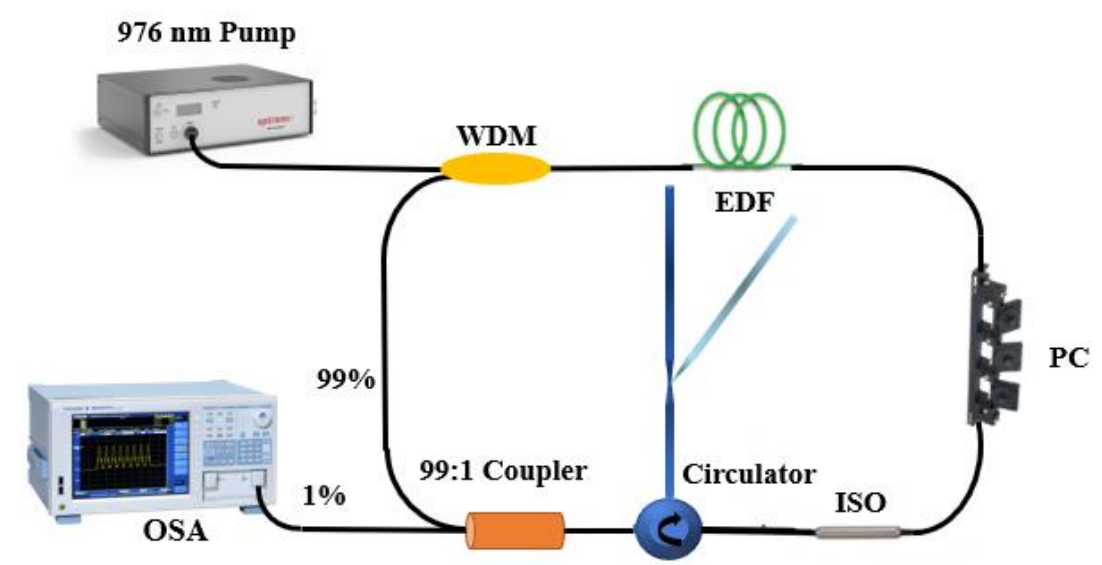

Figure 4. Experiment setup of the proposed fiber laser inclinometer.

When the inclinometer bends, the reflection attenuates strongly at the waist of the tFBG. The bend leaks the laser intensity. The relationship between normalized reflectance coefficient $(\mathrm{H})$ and $\beta$ can be simply expressed as follows [18]:

$$
H=p e^{-q \beta^{2}}
$$

In Equation (3), $p$ and $q$ are constants of the exponential fitting curve related to the sensitivity of the inclinometer, and the value of $p$ can be equivalent to the total response in the whole measurement range. $q$ is the attenuation coefficient of the Gaussian curve in Equation (3). According to Equation (3), $\theta$ can be easily determined as follows [18]:

$$
\beta=\sqrt{\frac{1}{q} \ln \left(\frac{H}{p}\right)}
$$

In the view of Equation (2), the $\theta$ can be estimated when the values of $R$ are measured. The sensitivity of Equation (1) with respect to $\theta$ can be obtained by differentiation as follows [18]:

$$
S=\frac{|d H|}{d \theta}
$$

As shown in Figure 5, the rotation platform is designed to detect the angle. The rotation angle is adjusted by rotating the nut. By monitoring the light intensity change of the optical power meter, real-time angle monitoring is realized. 


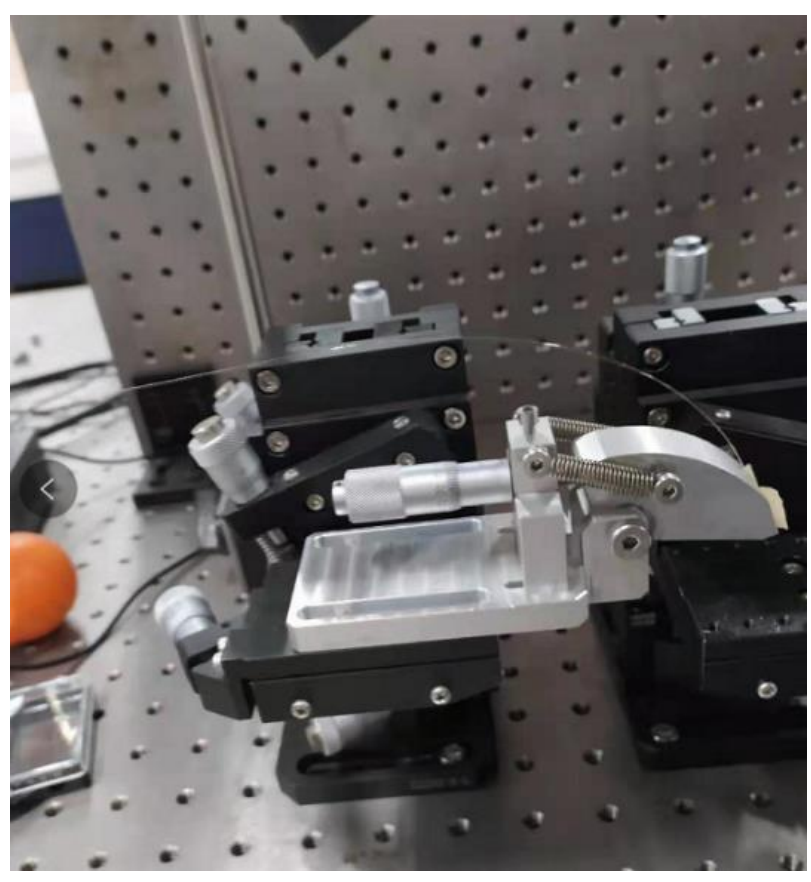

Figure 5. Experimental setup of turntable.

\section{Experimental Results}

As shown in Figure 3, pre-experimental results of the inclinometer working in broadband light source is observed. A supercontinuum light source, (ASE-C-N, Hoyatek, Shenzhen, China), an optical spectrum analyzer (OSA, AQ6370D, Yokogawa, Japan) and a circulator are included. The three-port optical circulator works in the wavelength range of $1550 \pm 20 \mathrm{~nm}$, which provides the manipulation of the reflection mode and the direction of the light in tFBG. The termination of the FBG is used as the reflector decreasing the retroreflections. The power and intensity fluctuation of reflected light are as low as $\pm 0.009 \mathrm{db} / \mathrm{mi}$ and $\pm 0.005 \mathrm{db} / \mathrm{min}$, which indicates that the tilt measurement has good stability. Besides, the optical power meter can be used to replace the OSA to cut down the system cost. As shown in Figure 6, the curvature is measured by optical power meter and spectrometer, respectively. The experimental results show consistency. The black and red lines in Figure 6 almost coincide. Therefore, the optical power meter is a reliable and effective cheap detection instrument.

The reflected light intensity of the inclinometer in broadband light source under different angles is analyzed at the range of $0^{\circ}$ to $40^{\circ}$ by a Yokogawa AQ6370D spectrometer (wavelength resolution is $0.02 \mathrm{~nm}$ ). The intensity of reflected light varies with the tilt angle as shown in Figure 7 . With the increase of tilt angle, the light intensity enters the cladding mode through the core mode of tFBG, resulting in partial energy loss. To quantify this phenomenon, the relationship between inclination angle and the reflectively is plotted in Figure 8. A consistent linear relationship exists. As the inclination angle e increases, the reflectively decreases, which is consistent with our previous analysis. The sensitivity of the sensor is $0.495 \mathrm{dBm} /{ }^{\circ}$ and the $\mathrm{R}^{2}$ of linear fitting is 0.991 . 


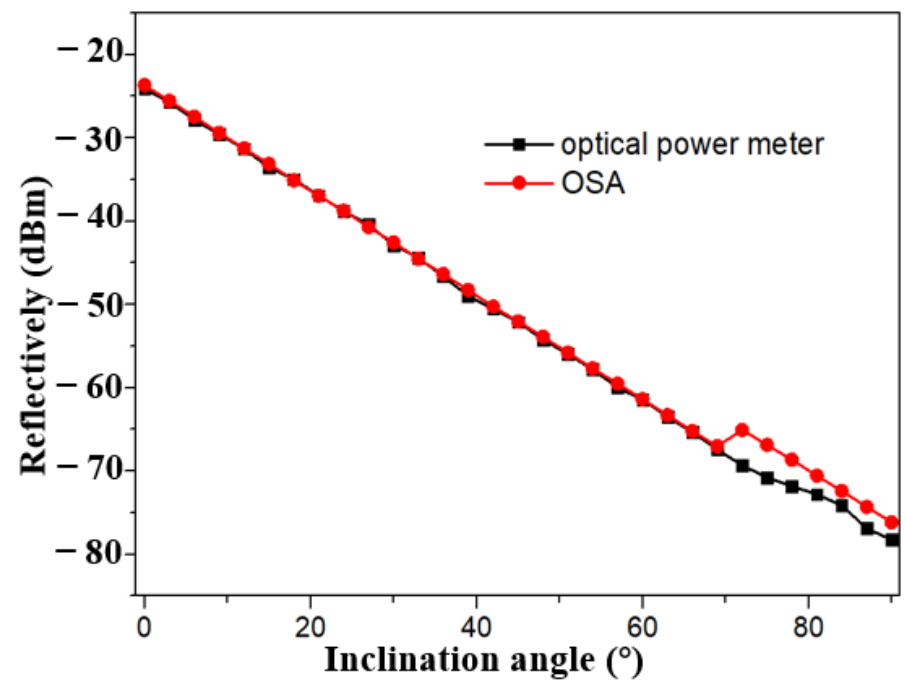

Figure 6. Optical power at peak reflection wavelength for various inclination angle (red line: optical power meter; black line: OSA).

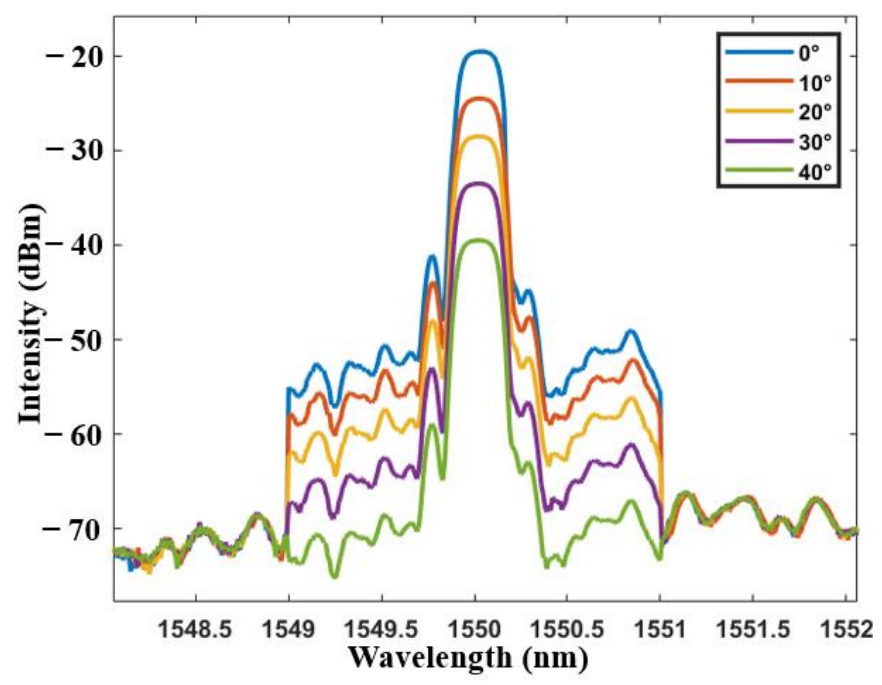

Figure 7. Transmission spectra of the tFBG at different angles.

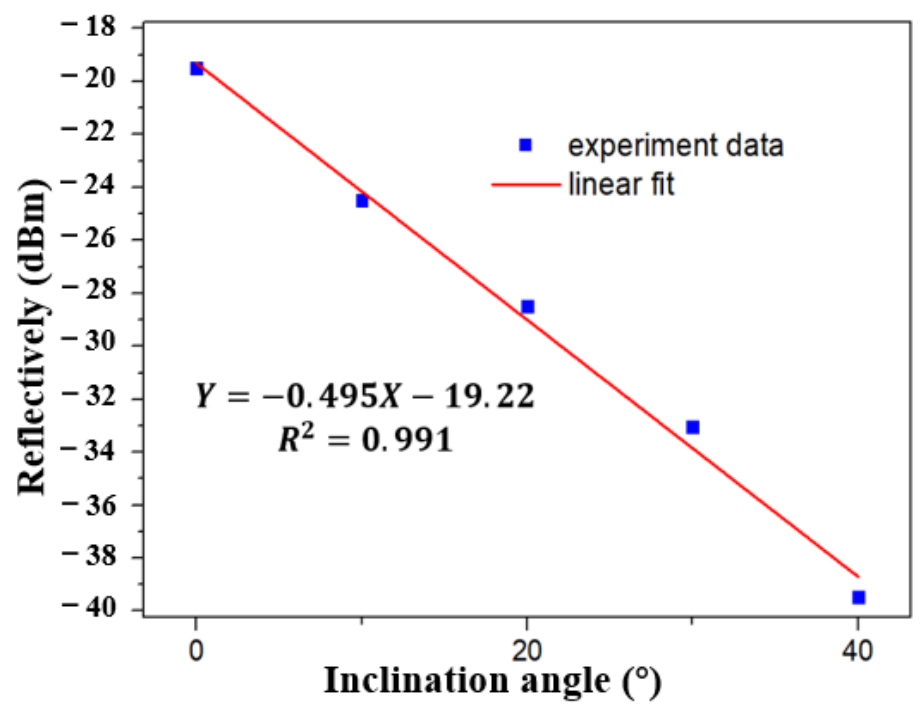

Figure 8. Linear fitting result of the relationship between reflectively and inclination angle. 
The inclinometer is accurately installed on the displacement platform. This means that the angle will be mechanically controlled by the turntable. The spectrum information can be demonstrated specifically by controlling the rotation of the mechanical platform. Firstly, the rotation angle of the turntable is controlled in the pre-experiment. For observing the change of light intensity more accurately, the rotation step is $10^{\circ}$. In practical application the tFBG sensor needs to be packaged to improve the stability. Nevertheless, the spectrum of the broadband light source measuring the inclination angle is disturbed, which may lead to the inaccuracy of the selected data, as shown in Figure 7. Moreover, the low detection sensitivity may affect the resolution of the inclinometer and increase the error, resulting in the decrease of usability.

The performance of inclinometer in FRL system is verified immediately, as shown in Figure 9. At first, tFBG with waist of $86 \mu \mathrm{m}$ and the distance from bending area to FBG center of $1.9 \mathrm{~mm}$ was selected as inclinometer. The light intensity decreases with the increase of inclination angle. As shown in Figures 10 and 11, a stable linear relationship is maintained in the measurement range of $0 \sim 80^{\circ}$. The sensitivity of the inclinometer is between $-0.849 \mathrm{dBm} /{ }^{\circ}$ and $-0.868 \mathrm{dBm} /{ }^{\circ}$. The $\mathrm{R}^{2}$ of linear fitting is 0.992 , as shown in Figure 10. Compared with the broadband light source, the sensitivity is further improved because of the more concentrated light intensity distribution in the laser cavity. As shown in Figure 11, for the sake of further demonstrated the resolution of inclinometer in FRL system. The experimental results show that the sensitivity of the sensor is $0.849 \mathrm{dbm} /{ }^{\circ}$ with detection step of $3^{\circ}$, which is consistent with the result of $0.868 \mathrm{dbm} /{ }^{\circ}$ as shown in Figure 10 . The $\mathrm{R}^{2}$ of linear fitting is 0.999 , which verifies the reliability and stability of the system. The result show that the detection resolution of inclinometer is better than $3^{\circ}$.

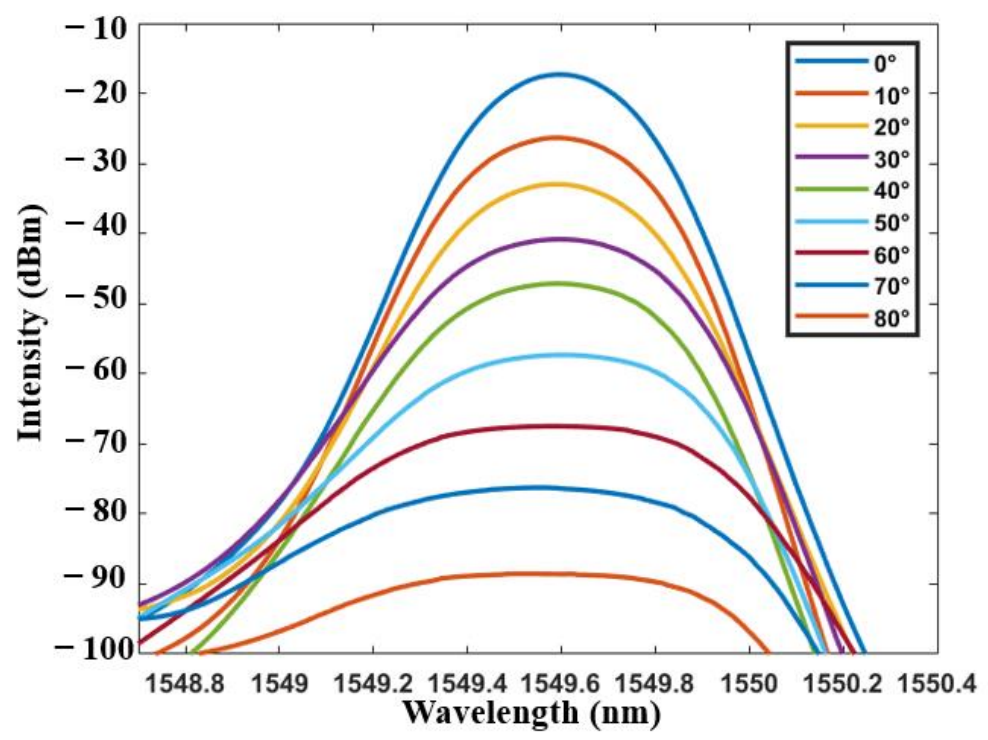

Figure 9. The dependence of the reflection spectrum at the wavelength of the reflection peak at different inclination angles in FRL with waist equals $86 \mu \mathrm{m}$. 


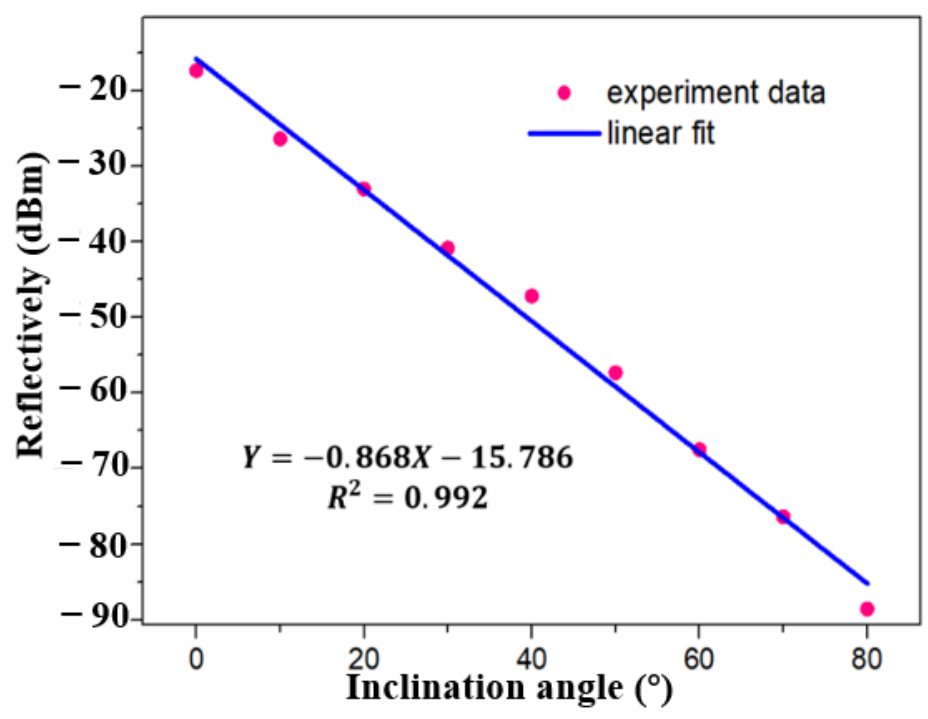

Figure 10. Linear fitting result of the relationship between reflectively and inclination angle in FRL system with step of $10^{\circ}$ with waist equals $86 \mu \mathrm{m}$.

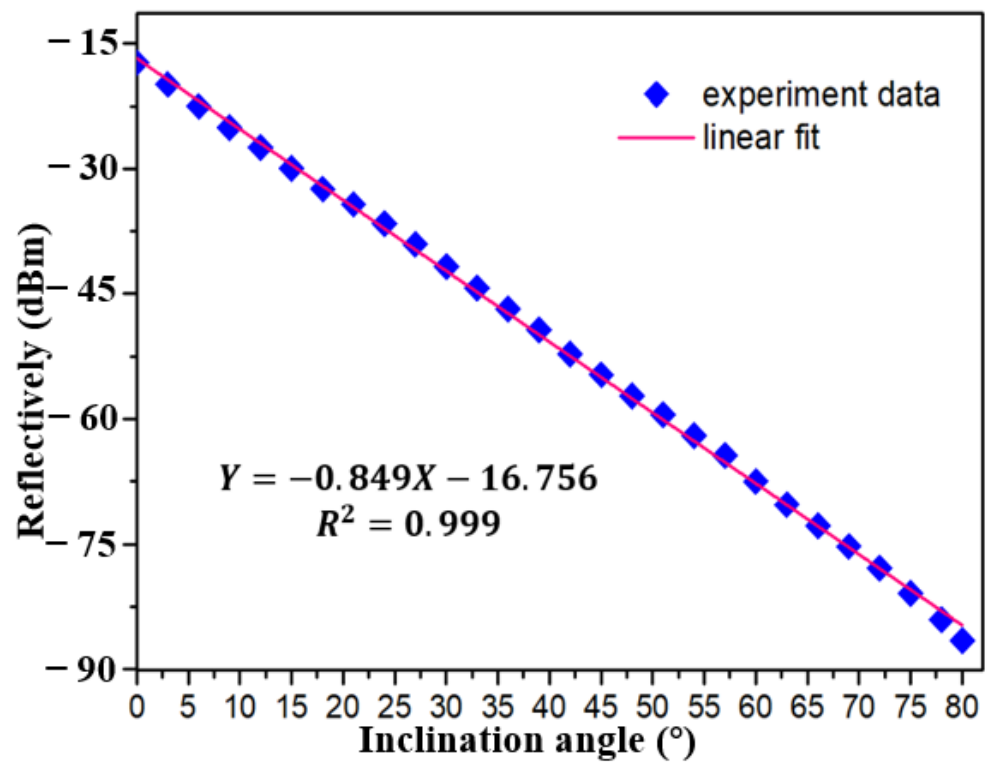

Figure 11. Linear fitting result of the relationship between reflectively and inclination angle in FRL system with step of $3^{\circ}$.

As mentioned above, the system can be further used as a temperature sensor. Figure 12 shows the transmission spectra of the tFBG at different temperature with the tapered fiber waist of $86 \mu \mathrm{m}$. It can be seen from the Figure 12 that the spectrum moves smoothly without the light intensity change under the range of 0 to $80^{\circ}$. As shown in Figure 13, the temperature sensing characteristics remain consistence when the inclination angle changes in a large range $\left(80^{\circ}\right)$. The temperature sensitivity of the inclinometer as a temperature sensor is $12 \mathrm{pm} /{ }^{\circ} \mathrm{C}$, which is a representative value of a FBG. The result is affected by the thermal expansion coefficient of the single mode fiber. Besides, the experimental results show that the transformation of light intensity is smaller than $0.05 \mathrm{dBm}$ at the range of $0{ }^{\circ} \mathrm{C}$ to $50^{\circ} \mathrm{C}$, which is negligible for an inclinometer. 


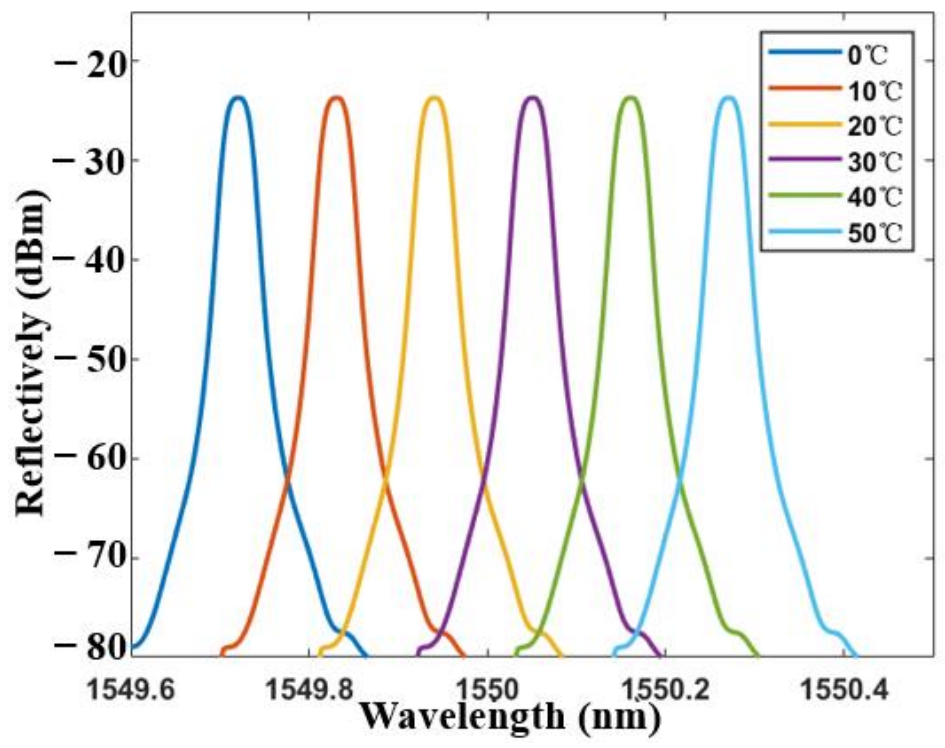

Figure 12. Transmission spectra of the tFBG at different temperature.

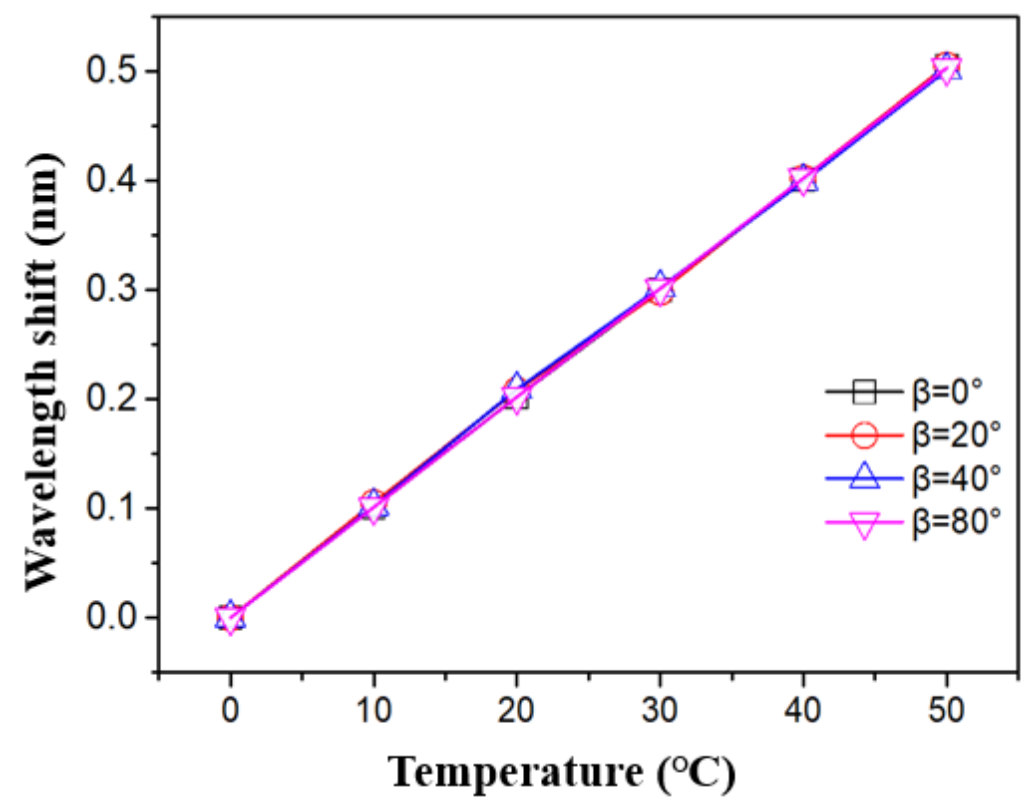

Figure 13. The influence of temperature on a wavelength shift.

The relationship between the measured total optical power and the inclination angle of the reflection spectrum is shown in Figure 14, when the tFBG waist becomes $75 \mu \mathrm{m}$. Under this condition, care should be taken to minimize any unnecessary back reflections in the system. As shown in Figure 15 . The sensitivity is $0.631 \mathrm{dBm} /{ }^{\circ}$ and $\mathrm{R}^{2}$ of linear fitting is 0.991 . As shown in Figure 16, we can further explore the detection resolution of the inclinometer. The experimental results show that the sensitivity is $0.631 \mathrm{dBm} /{ }^{\circ}$ and the $\mathrm{R}^{2}$ of the linear fit is 0.994 with the detection step of $3^{\circ}$. The discrepancy may be caused by residual strains and mechanical errors. The experimental results show that the detection resolution of the inclinometer is better than $3^{\circ}$. 


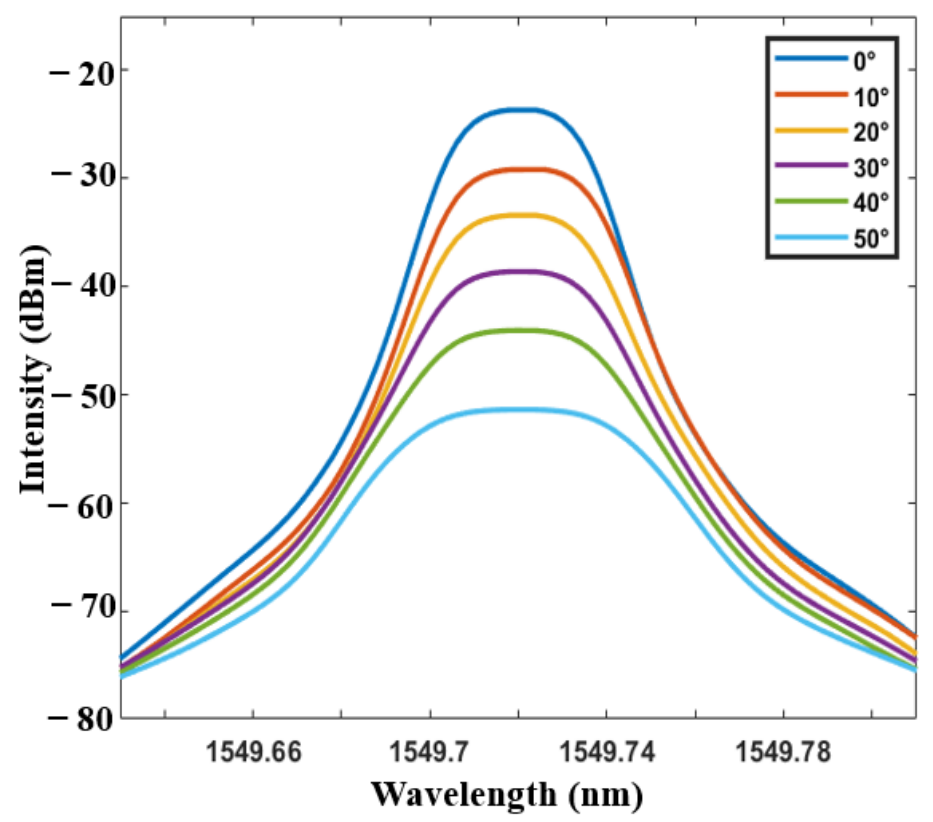

Figure 14. The dependence of the reflection spectrum at the wavelength of the reflection peak at different inclination angles in FRL with waist equals $75 \mu \mathrm{m}$.

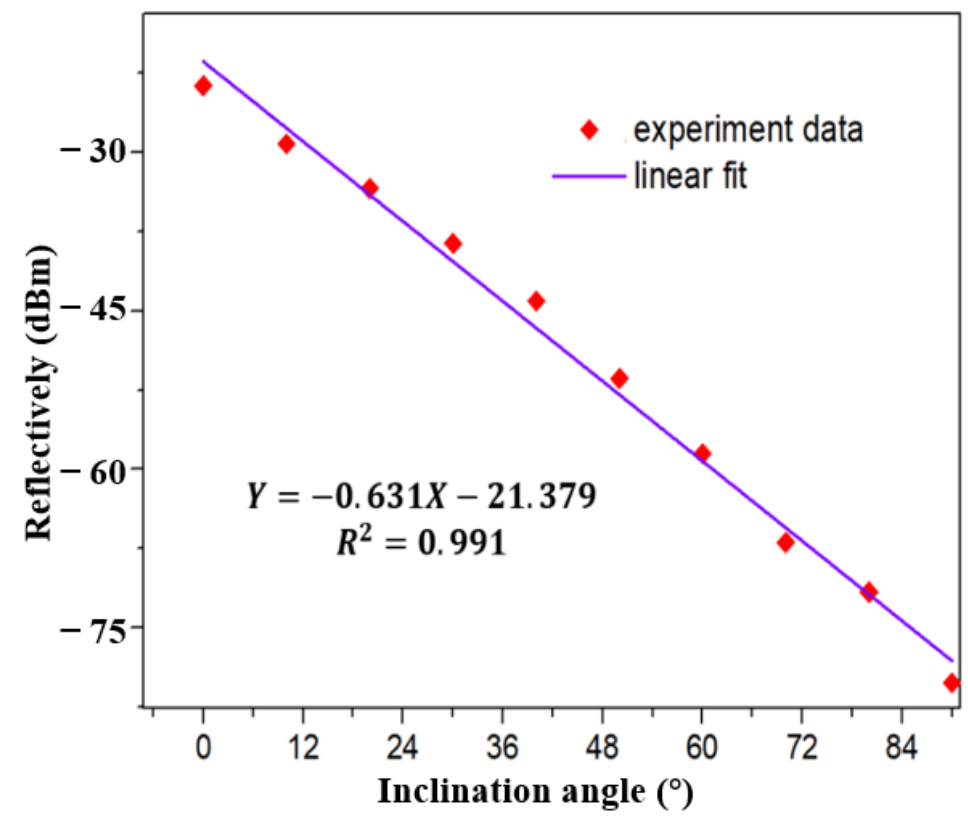

Figure 15. Linear fitting result of the relationship between reflectively and inclination angle in FRL system with step of $10^{\circ}$ with waist equals $15 \mu \mathrm{m}$.

When the waist width of TFBG is $75 \mu \mathrm{m}$, the FRL system can produce a single longitudinal mode laser output with a bandwidth of $0.04 \mathrm{~nm}$ and a signal-to-noise ratio of $50 \mathrm{~dB}$, as shown in Figure 14. Wavelength shift and power fluctuation were also detected. As shown in Figure 17, within $250 \mathrm{~min}$, the laser energy and wavelength fluctuate in the range of $\pm 0.52 \mathrm{dBm} / \mathrm{h}$ and $\pm 0.43 \mathrm{~nm} / \mathrm{h}$, respectively. The analysis shows that the designed $\mathrm{tFBG}$ is easy to be affected by the external stress because it is not packaged. This will lead to the deviation of light intensity stability. To further improve the practical application ability and accuracy of the system. Flexible materials such as PDMS and PMMA can be selected as packaging devices. 


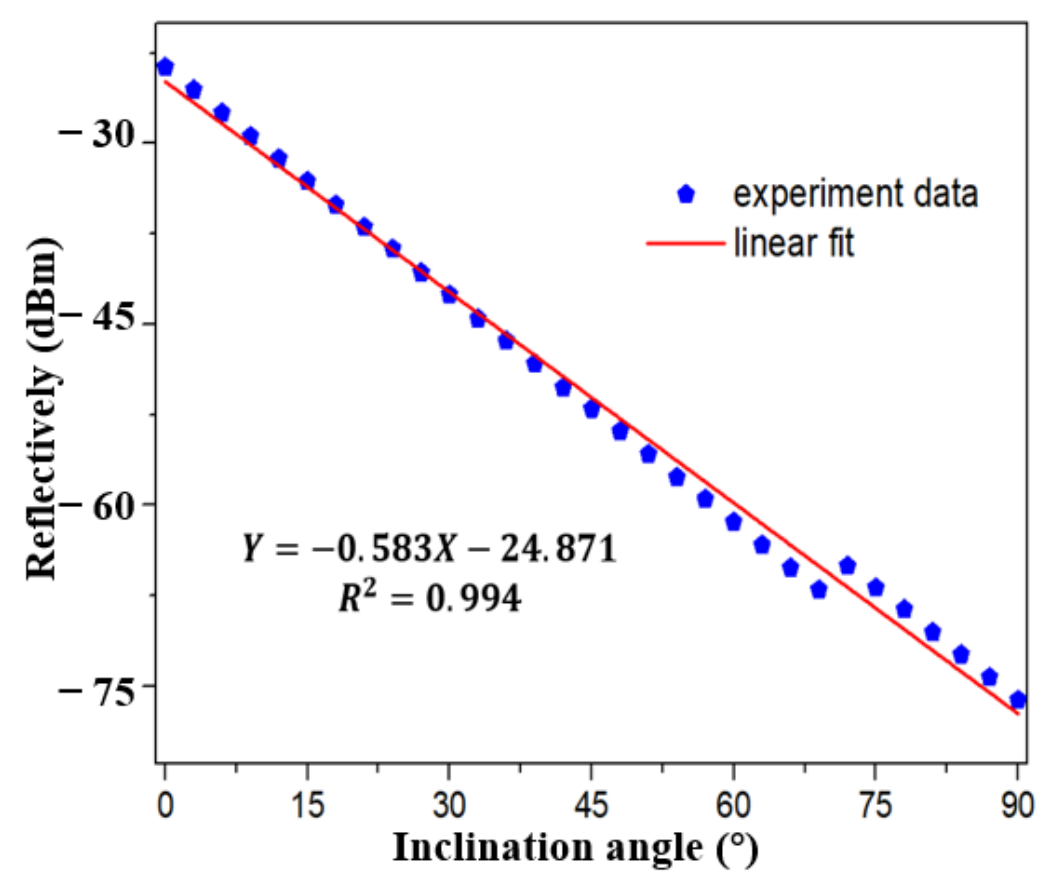

Figure 16. Linear fitting result of the relationship between reflectively and inclination angle in FRL system with step of $3^{\circ}$.

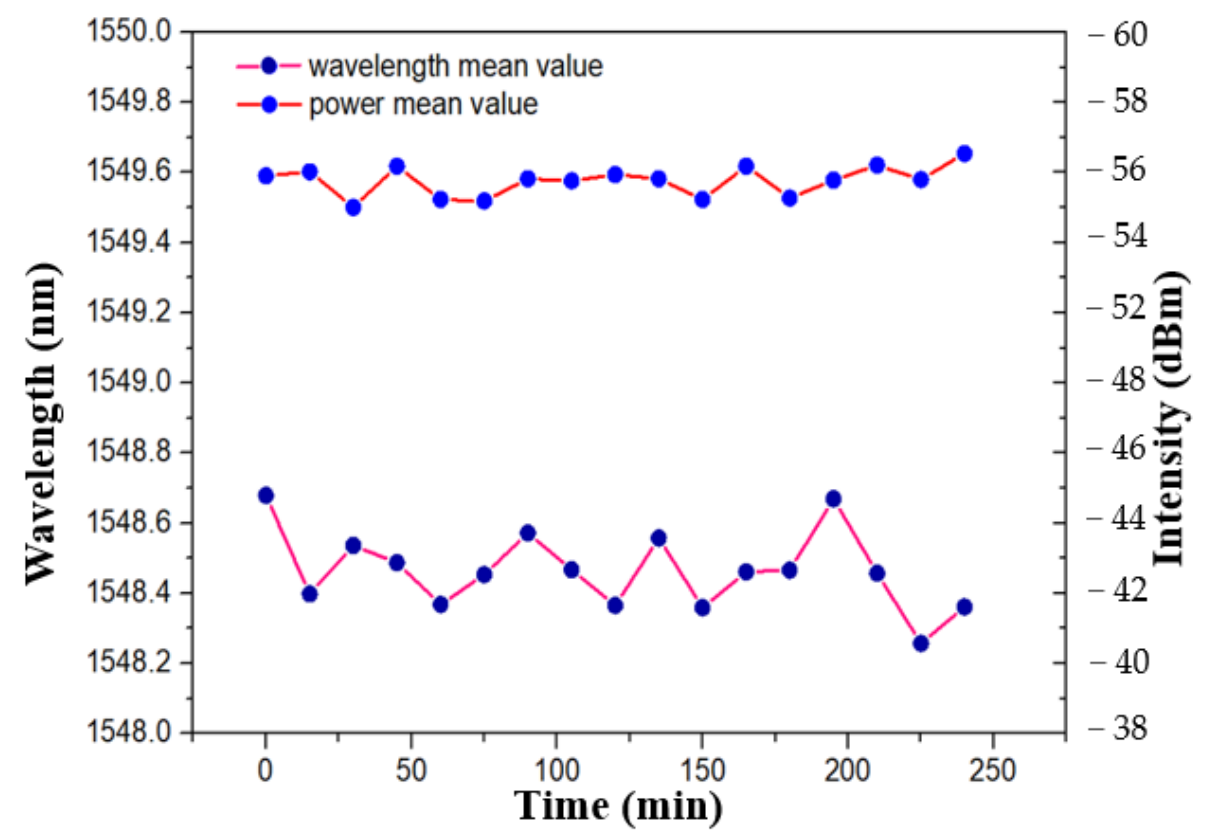

Figure 17. Test for time stability of wavelength shift and power fluctuation (at $51^{\circ}$ ).

\section{Discussion}

The proposed inclinometer based on tFBG in a FRL system was compared with other inclinometers like those described in references [40-48]. The inclination angle range is shown in Table 1. The proposed inclinometer is an impactful method to enhance the detection range. The bound of response rate is principal owing to the tapered lengths, and there are some issues could be improved further in the future. 
Table 1. The detection range comparation with other optical fiber inclinometer.

\begin{tabular}{ccc}
\hline Structures & Tilt Angle & References \\
\hline Tilted fiber Bragg grating & $-12-12^{\circ}$ & {$[40]$} \\
Tapered Polymer Fiber & $-6-6^{\circ}$ & {$[18]$} \\
Peanut-Shape Structure & $0-6.66^{\circ}$ & {$[41]$} \\
Fiber Bragg Grating & $0-1^{\circ}$ & {$[42]$} \\
A couple of matched FBGs & $-6^{\circ}$ & {$[43]$} \\
Cascaded FBG & $/$ & {$[44]$} \\
all-fiber loop mirror & $-45-45^{\circ}$ & {$[45]$} \\
small size Fiber Bragg Grating & $-3-3^{\circ}$ & {$[46]$} \\
fiber Bragg grating-based inclinometer & $/$ & {$[47]$} \\
extrinsic Fabry-Perot interferometer & $0-8^{\circ}$ & {$[48]$} \\
Current work & $0-90^{\circ}$ & \\
\hline
\end{tabular}

The sensitivity of the inclinometer working with the laser is almost twice that achieved when working with a broadband light source. Besides, the sensitivity can be improved by changing the taper depth and position. In addition, if the waist is too thin, the light intensity will leak out at a very small angle, which impact the detection range. Here, our proposed inclinometer cannot define the direction. The problem could be solved by chosing a tilted fiber grating. Figure 18a shows the tapered FBG with waist equal to $50 \mu \mathrm{m}$. However, dust hast a great impact on the experimental results. Therefore, a $86 \mu \mathrm{m}$ waist is selected.

Regarding repeatability and reproducibility, the inclinometer has been used several times ( $>10$ times) with change in measurands and we find similar outcomes each time. The computed value the error of the measurement is on the order of $10^{-3}$. The sensors were used for repeated experiments quite a few time ( $>10$ times and $>5 \mathrm{~h}$ ) and the results were similar.

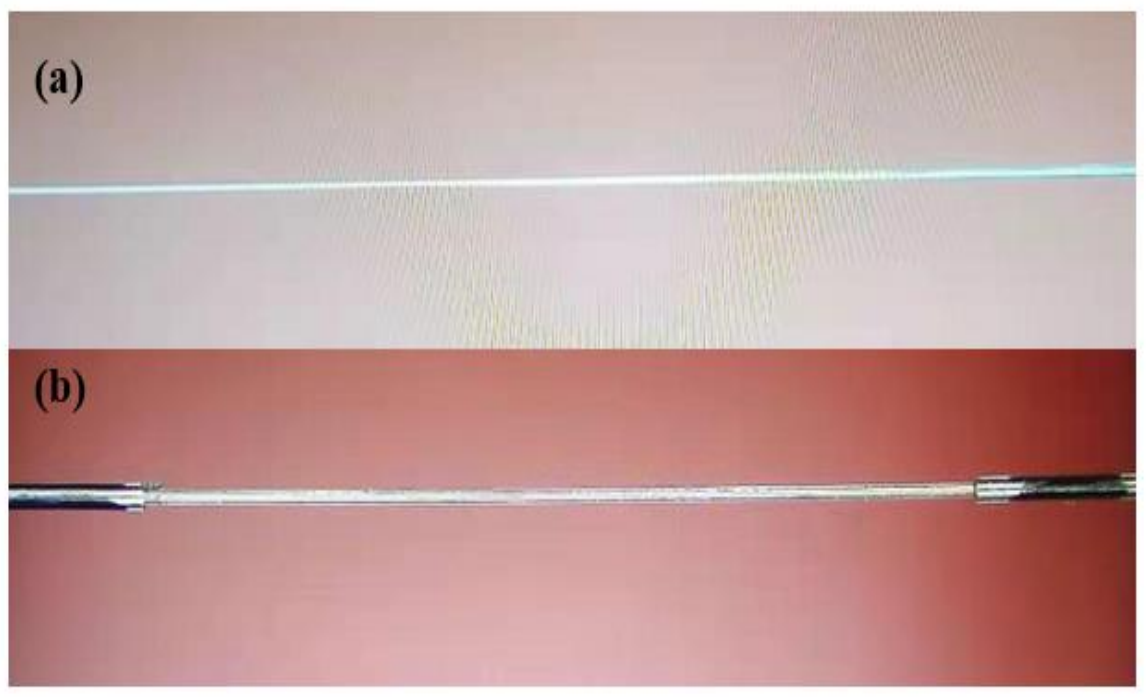

Figure 18. Scheme of the (a) FBG with waist of $50 \mu \mathrm{m}$ (b) normal FBG.

\section{Conclusions}

In conclusion, an inclinometer based on tFBG in a FRL structure is proposed and demonstrated. The inclinometer has the ability to simultaneously monitor inclination and temperature. The sensitivity is $0.849 \mathrm{dBm} /{ }^{\circ}$ and $0.583 \mathrm{dBm} /{ }^{\circ}$, respectively with a detection range from $0^{\circ}$ to $90^{\circ}$. For temperature sensing, sensitivity of $12 \mathrm{pm} /{ }^{\circ} \mathrm{C}$ is achieved without fluctuating light intensity. This new concept of an inclinometer based on tFBG in FRL structure provides the following advantages: (a) narrow 3-dB bandwidth $(<0.1 \mathrm{~nm})$ and high optical signal-to-noise ratio ( $\sim 60 \mathrm{~dB})$ are achieved. (b) An increase in the light intensity since the FRL system has better spectral response. (c) Consistency of the temperature 
response under different inclinometer angles. (d) A low-cost optical power meter can be used to replace OSA for tilt measurements. Moreover, the proposed inclinometer has the advantages of compact size and convenient manufacture, enhancing its application prospects.

Author Contributions: Conceptualization, W.L. and L.S.; methodology, W.L.; software, S.Z.; validation, Y.L. (Yibin Liu), Y.L. (Yuhui Liu) and P.-P.S.; formal analysis, M.I.V.; investigation, S.L.; resources, W.X.; data curation, F.Y.; writing-original draft preparation, F.Z.; writing-review and editing, W.L.; visualization, L.S.; supervision, L.S.; project administration, M.I.V.; funding acquisition, S.L. All authors have read and agreed to the published version of the manuscript.

Funding: This work was supported by the startup fund from Southern University of Science and Technology and Shenzhen government.

Institutional Review Board Statement: Not applicable.

Informed Consent Statement: Not applicable.

Data Availability Statement: Not applicable.

Conflicts of Interest: The authors declare no conflict of interest.

\section{References}

1. Wei, B.; Feng, P.; Mi, D.L.; Ren, Y.; Yang, F.; Zhao, Q.H. A Gyro-Based Inclinometer for Oil and Gas Well Logging. Appl. Mech. Mater. 2012, 152-154, 889-893. [CrossRef]

2. Li, S.; Peng, X. Safety monitoring of underground steel pipeline subjected to soil deformation using wireless inclinometers. J. Civ. Struct. Health Monit. 2016, 6, 739-749. [CrossRef]

3. Klotz, T.; Pothier, R.; Walch, D.; Colombo, T. Prediction of the business jet Global 7500 wing deformed shape using fiber Bragg gratings and neural network. Results Eng. 2021, 9, 100190. [CrossRef]

4. Ranganathan, N.; Patel, M.I.; Sathyamurthy, R. An intelligent system for failure detection and control in an autonomous underwater vehicle. IEEE Trans. Syst. Man Cybern. Part A Syst. Hum. 2001, 31, 762-767. [CrossRef]

5. Júdice, P.B.; Teixeira, L.; Silva, A.M.; Sardinha, L.B. Accuracy of Actigraph inclinometer to classify free-living postures and motion in adults with overweight and obesity. J. Sports Sci. 2019, 37, 1708-1716. [CrossRef]

6. Manaf, A.B.A.; Nakamura, K.; Matsumoto, Y. One-side-electrode-type fluid-based inclinometer combined with complementary metal oxide semiconductor circuitry. Sens. Mater 2007, 19, 417-434.

7. Li, Z.; Durgin, F.H. Design, data, and theory regarding a digital hand inclinometer: A portable device for studying slant perception. Behav. Res. Methods 2011, 43, 363-371. [CrossRef]

8. Tariq, H.; Touati, F.; Al-Hitmi, M.A.E.; Crescini, D.; Ben Mnaouer, A.; Al-Hitmi, M.E. A Real-Time Early Warning Seismic Event Detection Algorithm Using Smart Geo-Spatial Bi-Axial Inclinometer Nodes for Industry 4.0 Applications. Appl. Sci. 2019, 9, 3650. [CrossRef]

9. Ayala, F.; de Baranda, P.S.; Croix, M.D.S.; Santonja, F. Reproducibility and Concurrent Validity of Hip Joint Angle Test for Estimating Hamstring Flexibility in Recreationally Active Young Men. J. Strength Cond. Res. 2012, 26, 2372-2382. [CrossRef]

10. Pei, H.; Jing, J.; Zhang, S. Experimental study on a new FBG-based and Terfenol-D inclinometer for slope displacement monitoring. Measurement 2020, 151, 151. [CrossRef]

11. Zheng, D.; Cai, Z.; Floris, I.; Madrigal, J.; Pan, W.; Zou, X.; Sales, S. Temperature-insensitive optical tilt sensor based on a single eccentric-core fiber Bragg grating. Opt. Lett. 2019, 44, 5570-5573. [CrossRef]

12. Kinjalk, K.; Kumar, A.; Gautam, A. High-Resolution FBG-Based Inclination Sensor Using Eigen Decomposition of Reflection Spectrum. IEEE Trans. Instrum. Meas. 2020, 69, 9124-9131. [CrossRef]

13. Yan, Z.; Zheng, D.J;; Chen, Z.Y.; Liu, Y.T. Research on a novel inclinometer based on distributed optical fiber strain and conjugate beam method. Measurement 2020, 153, 107404.

14. Guo, C.; Chen, D.; Shen, C.; Lu, Y.; Liu, H. Optical inclinometer based on a tilted fiber Bragg grating with a fused taper. Opt. Fiber Technol. 2015, 24, 30-33. [CrossRef]

15. Zhang, S.; Zhang, W.; Geng, P.; Wang, L. A Mach-Zehnder interferometer constructed using lateral offset and a long period fiber grating for two-dimensional bending vector sensing. J. Opt. 2013, 16. [CrossRef]

16. Hong, C.; Zhang, Y.; Abro, Z.A. A Fiber Bragg Grating-Based Inclinometer Fabricated Using 3-D Printing Method for Slope Monitoring. Geotech. Test. J. 2019, 43. [CrossRef]

17. Cui, J.; Gunawardena, D.; Liu, Z.; Zhao, Z.; Tam, H.-Y. All-Fiber Two-Dimensional Inclinometer Based on Bragg Gratings Inscribed in a Seven-Core Multi-Core Fiber. J. Light. Technol. 2020, 38, 2516-2522. [CrossRef]

18. Lee, C.L.; Zeng, R.C.; Yang, C.R.; Lin, C.F.; Ma, C.T.; Liu, W.F. Tapered Polymer Fiber Inclinometers. IEEE Photonics J. 2020, $12,1$. [CrossRef]

19. Osuch, T.; Markowski, K.; Jędrzejewski, K. Temperature Independent Tapered Fiber Bragg Grating-Based Inclinometer. IEEE Photon Technol. Lett. 2015, 27, 2312-2315. [CrossRef] 
20. Cai, X.; Luo, J.; Fu, H.; Bu, Y.; Chen, N. Temperature measurement using a multi-wavelength fiber ring laser based on a hybrid gain medium and Sagnac interferometer. Opt. Express 2020, 28, 39933-39943. [CrossRef]

21. Yang, F.; Wu, Y.J.; Shi, J.; Yang, K.; Xu, W.; Guo, C.J.; Bai, H.; Zhang, S.S.; Xu, D.G.; Fu, W.L.; et al. Curvature sensor based on fiber ring laser with Sagnac loop. Opt. Fiber Technol. 2020, 60, 102341. [CrossRef]

22. Tian, J.; Hou, M.-J.; Jiang, Y.; Luo, H.; Tang, C.-Y. Fiber ring laser cavity for strain sensing via beat frequency demodulation. Opt. Commun. 2020, 476, 126326. [CrossRef]

23. Zhang, Y.; Bu, X. Narrow linewidth erbium-doped fiber laser incorporating with photonic crystal fiber based Fabry-Pérot interferometer for temperature sensing applications. Optik 2020, 219, 165005. [CrossRef]

24. Kuznetsov, P.I.; Sudas, D.P.; Savel'Ev, E.A. Formation of Fiber Tapers by Chemical Etching for Application in Fiber Sensors and Lasers. Instrum. Exp. Tech. 2020, 63, 516-521. [CrossRef]

25. Arumona, A.E.; Garhwal, A.; Youplao, P.; Amiri, I.S.; Ray, K.; Punthawanunt, S.; Yupapin, P. Electron Cloud Spectroscopy Using Micro-Ring Fabry-Perot Sensor Embedded Gold Grating. IEEE Sens. J. 2020, 20, 10564-10571. [CrossRef]

26. Ma, K.; Song, N.; Jin, J.; He, J.; Zio, E. Configuration Optimization in Miniature Interferometric Fiber-Optic Gyroscopes for Space Application. IEEE Sens. J. 2020, 20, 7107-7117. [CrossRef]

27. Perez-Herrera, R.A.; Stancalie, A.; Cabezudo, P.; Sporea, D.; Negut,, D.; Lopez-Amo, M. Gamma Radiation-Induced Effects over an Optical Fiber Laser: Towards New Sensing Applications. Sensors 2020, 20, 3017. [CrossRef]

28. Zhang, L.; Tian, Z.; Chen, N.K.; Han, H.; Liu, C.N.; Grattan, K.T.; Rahman, B.M.A.; Zhou, H.; Liaw, S.K.; Bai, C. Room-Temperature Power-Stabilized Narrow-Linewidth Tunable Erbium-Doped Fiber Ring Laser Based on Cascaded Mach-Zehnder Interferometers With Different Free Spectral Range for Strain Sensing. J. Light. Technol. 2020, 38, 1966-1974. [CrossRef]

29. Martin-Vela, J.A.; Sierra-Hernandez, J.M.; Jauregui-Vazquez, D.; Estudillo-Ayala, J.M.; Hernandez-Garcia, J.C.; Reyes-Ayona, J.R.; Garcia-Mina, D.F.; Rojas-Laguna, R. Highly Sensitive Fiber Ring Laser Sensor for Curvature Using a Modal Interferometer. IEEE Sens. J. 2020, 20, 9864-9870. [CrossRef]

30. Yang, S.; Xiang, Z.; Fu, H.; Wang, Y. Temperature sensing scheme based on fiber ring microwave photonic filter with erbium doped fiber amplification. Microw. Opt. Technol. Lett. 2019, 62, 1477-1482. [CrossRef]

31. Madry, M.; Alwis, L.; Binetti, L.; Pajewski, L.; Beres-Pawlik, E. Simultaneous Measurement of Temperature and Relative Humidity Using a Dual-Wavelength Erbium-Doped Fiber Ring Laser Sensor. IEEE Sens. J. 2019, 19, 9215-9220. [CrossRef]

32. Li, T.; Tan, Y.; Han, X.; Zheng, K.; Zhou, Z. Diaphragm Based Fiber Bragg Grating Acceleration Sensor with Temperature Compensation. Sensors 2017, 17, 218. [CrossRef]

33. Leal-Junior, A.; Theodosiou, A.; Díaz, C.; Marques, C.; Pontes, M.J.; Kalli, K.; Frizera-Neto, A. Polymer Optical Fiber Bragg Gratings in CYTOP Fibers for Angle Measurement with Dynamic Compensation. Polymers 2018, 10, 674. [CrossRef]

34. Marques, C.A.; Leal-Junior, A.G.; Min, R.; Domingues, M.; Leitao, C.; Antunes, P.; Ortega, B.; André, P. Advances on Polymer Optical Fiber Gratings Using a KrF Pulsed Laser System Operating at $248 \mathrm{~nm}$. Fibers 2018, 6, 13. [CrossRef]

35. Wang, J.; Huang, T.; Duan, F.; Cheng, Q.; Zhang, F.; Qu, X. Fast peak-tracking method for FBG reflection spectrum and nonlinear error compensation. Opt. Lett. 2020, 45, 451. [CrossRef]

36. Ogawa, K.; Koyama, S.; Haseda, Y.; Fujita, K.; Ishizawa, H.; Fujimoto, K. Wireless, Portable Fiber Bragg Grating Interrogation System Employing Optical Edge Filter. Sensors 2019, 19, 3222. [CrossRef]

37. Kim, K.-T.; Kang, J.-H.; Hwangbo, S.; Im, K.-G. In-line Variable Optical Attenuator Based on the Bending of the Tapered Single Mode Fiber. J. Opt. Soc. Korea 2009, 13, 349-353. [CrossRef]

38. Marcuse, D. Curvature loss formula for optical fibers. J. Opt. Soc. Am. 1976, 66, 216-220. [CrossRef]

39. Shao, L.-Y.; Albert, J. Compact fiber-optic vector inclinometer. Opt. Lett. 2010, 35, 1034-1036. [CrossRef] [PubMed]

40. Gong, H.; Qian, Z.; Yang, X.; Zhao, C.-L.; Dong, X. Optical Fiber Inclinometer Based on a Fiber Taper Cascading a Peanut-Shape Structure. IEEE Sens. J. 2015, 15, 3917-3920. [CrossRef]

41. Yang, Y.; Ma, X.; Chen, K.; Wang, E.; Yu, Z.; Yu, Q. A high-resolution dynamic fiber-optic inclinometer. Sens. Actuators A Phys. 2018, 283, 305-312. [CrossRef]

42. Maheshwari, M.; Yang, Y.; Upadrashta, D.; Chaturvedi, T. A Rotation Independent In-Place Inclinometer/Tilt Sensor Based on Fiber Bragg Grating. IEEE Trans. Instrum. Meas. 2018, 68, 2943-2953. [CrossRef]

43. Zheng, Y.; Zhu, Z.-W.; Deng, Q.-X.; Xiao, F. Theoretical and experimental study on the fiber Bragg grating-based inclinometer for slope displacement monitoring. Opt. Fiber Technol. 2019, 49, 28-36. [CrossRef]

44. Momosaki, R.; Kumar, A.; Kumar, N.; Ojha, N.S. Polarization induced non-reciprocal phase controlled all-fiber loop mirror based inclinometer. Opt. Laser Technol. 2019, 112, 134-139. [CrossRef]

45. Xu, H.; Li, F.; Zhao, W.; Wang, S.; Du, Y.; Bian, C. A High Precision Fiber Bragg Grating Inclination Sensor for Slope Monitoring. J. Sens. 2019, 2019, 1-7. [CrossRef]

46. Zheng, Y.; Huang, D.; Shi, L. A new deflection solution and application of a fiber Bragg grating-based inclinometer for monitoring internal displacements in slopes. Meas. Sci. Technol. 2018, 29, 055008. [CrossRef]

47. Zhuang, Y.; Chen, Y.; Zhu, C.; Gerald, R.E.; Huang, J. Probing changes in tilt angle with 20 nanoradian resolution using an extrinsic Fabry-Perot interferometer-based optical fiber inclinometer. Opt. Express 2018, 26, 2546-2558. [CrossRef] [PubMed]

48. Ji, C.; Zhao, C.-L.; Kang, J.; Dong, X.; Jin, S. Multiplex and simultaneous measurement of displacement and temperature using tapered fiber and fiber Bragg grating. Rev. Sci. Instrum. 2012, 83, 053109. [CrossRef] 